\title{
Anionic Surfactant as a Corrosion Inhibitor for Synthesized Ferrous Alloy in Acidic Solution
}

\author{
Farida Kellou-Kerkouche, Abdelkader Benchettara, and Sif-Eddine Amara \\ Laboratoire d'Electrochimie, Corrosion, Métallurgie et Chimie Minérale, Faculté de Chimie, USTHB, BP 32 El-Alia, \\ Bab Ezzouar, 16111 Alger, Algeria \\ Correspondence should be addressed to Farida Kellou-Kerkouche; kelfarida@yahoo.fr
}

Received 19 November 2012; Accepted 21 December 2012

Academic Editor: Belkheir Hammouti

Copyright (C) 2013 Farida Kellou-Kerkouche et al. This is an open access article distributed under the Creative Commons Attribution License, which permits unrestricted use, distribution, and reproduction in any medium, provided the original work is properly cited.

\begin{abstract}
The effect of temperature on the corrosion behaviour of a synthesized iron-based alloy in $1 \mathrm{~N}$ sulphuric acid solution has been examined by means of three electrochemical techniques. Thereafter, we studied the influence of an anionic surfactant (sodium dodecyl benzene sulfonate) at various concentrations on the electrochemical behaviour of the ferrous alloy. The obtained results show that the temperature increase reduced the performance of the used alloy, in the acidic environment. Otherwise, the surfactant inhibits the alloy dissolution in the sulphuric acid, through its adsorption on the metal surface without modifying the mechanism of corrosion process. We also noticed that the highest inhibition effect is obtained at a concentration above its critical micelle concentration (CMC). Langmuir adsorption isotherm fits well with the experimental data.
\end{abstract}

\section{Introduction}

The researches undertaken to clarify the mechanisms of the iron and the ferrous materials corrosion, in sulphuric acid environment, are uncountable because of the importance which takes on this phenomenon in particular for the industry [1-4].

Hydrochloric and sulphuric acids are regular aggressive solutions for acid pickling, acid cleaning, and acid descaling. To remove unwanted scale such as rust or mill scale formed during manufacture, ferrous materials are immersed in acidic solutions. Due to the aggressiveness of acids, inhibitors are often used to reduce the dissolution rate of metallic materials. A vast category of organic corrosion inhibitors is used for iron and ferrous alloys in sulphuric acid solutions [5-14].

Surfactants are used in several industrial processes such as flotation, emulsification, cosmetics, and corrosion inhibitors [15]. The application of surfactants as corrosion inhibitors has been widely studied, and adsorption of these molecules on the metal surface was found to be responsible for the corrosion inhibition of the metal [15-20].

The inhibitors can drastically change the interfacial properties, and their adsorption is influenced by surface charge of the metal, the type of corrosive solution, and the chemical structure of inhibitors. The principal types of interaction between an organic inhibitor and a metal surface are physical adsorption and chemical adsorption [21-23]. Electrostatic attraction between the charged hydrophilic groups and the charge active centres on the metal leads to physisorption.

The goal of this work is to study the sodium dodecyl benzene sulfonate (SDBS) effect as a corrosion inhibitor for an elaborated annealed alloy $\mathrm{Fe}-3 \mathrm{Ti}-2 \mathrm{C}$ in $1 \mathrm{~N}$ sulphuric acid solution containing dissolved dioxygen. The alloy surface presents ferritic matrix and titanium carbides. Three usual electrochemical techniques were recorded to examine the inhibition efficiency of SDBS. Besides, we also considered the influence of temperature on the SDBS inhibition effect.

\section{Experimental Process}

The elaboration protocol and the surface analysis of the alloy Fe-3Ti-2C are described in a previous paper [24].

For the electrochemical study, a cylindrical specimen was cut from the annealed ingot and embedded in resin dental. The cross-section of the working electrode $\left(0.652 \mathrm{~cm}^{2}\right.$ area $)$ 
was mechanically ground with emery paper up to 1200 grit, degreased in acetone, rinsed with bidistilled water, dried and transferred quickly in a Tacussel glass cell filled with $100 \mathrm{~mL}$ of $1 \mathrm{~N}$ sulphuric acid solution. A saturated sulphate electrode (SSE) and platinum electrode were used as reference and auxiliary electrodes, respectively. All measured potentials are reported to this reference electrode. The experiments were carried out in a naturally aerated and continuously stirred $1 \mathrm{~N}$ sulphuric acid solution in the absence and presence of different concentrations of sodium dodecyl benzene sulphonate (SDBS). Measurements were performed using a potentiostat/galvanostat PGZ 301 and controlled with Tacussel corrosion analysis software (Voltamaster 4). Potentiodynamic polarization curves were recorded at a scan rate of $60 \mathrm{mV} / \mathrm{min}$. Prior to electrochemical measurements, the working electrode was maintained at open circuit potential during $30 \mathrm{~min}$. Linear polarization $\left(R_{p}\right)$ measurements were carried out at $0.1 \mathrm{mV} / \mathrm{s}$. Polarization resistance $R_{p}$ was defined as the slope of polarization curve at the overpotential of $\pm 20 \mathrm{mV} / E_{\text {corr }}$. The EIS measurements were carried out at the corrosion potential $\left(E_{\text {corr }}\right)$ after 30 min of immersion in the studied solutions. Impedance spectra were obtained in the descending frequency range from $10 \mathrm{KHz}$ to $40 \mathrm{MHz}$, with ten points per decade. A sine wave with $10 \mathrm{mV}$ amplitude was used to perturb the system. The charge transfer resistance values $\left(R_{t}\right)$ were calculated from the difference in impedance at the lower and higher frequencies, as suggested by Tsuru et al. [25]. To obtain the double layer capacitance $\left(C_{\mathrm{dl}}\right)$, the frequency $(f)$ at which the imaginary component of the impedance is maximum $\left(Z_{\mathrm{im} \mathrm{max}}\right)$ was found, and $\left(C_{\mathrm{dl}}\right)$ values were obtained from the following equation:

$$
f\left(-Z_{\mathrm{im}}\right)_{\max }=\frac{1}{2 \pi C_{\mathrm{dl}} R_{t}} .
$$

\section{Results and Discussion}

In our previous study [24] we have showed that the microstructure of the considered alloy (Fe-3Ti-2C) is constituted by ferrite matrix and titanium carbides.

3.1. Temperature Effect on the Corrosion Behaviour of Fe3Ti-2C. We consider, at first, the temperature effect on the corrosion behaviour of the ternary alloy immersed in normal sulphuric acid solution; we will examine then its protection in the presence of the sodium dodecyl benzene sulphonate (SDBS).

\subsubsection{Potentiodynamic Polarization Curves. According to} Figure 1, the shape of the cathodic polarization curves related to the studied system is not affected by temperature increase; however they are shifted to the high current densities values. We can deduce that the proton discharge mechanism (the hydrogen evolution reaction (HER) is an activation controlled since the cathodic portions rise to the Tafel lines) is not modified by the temperature rise; nevertheless it is accelerated.

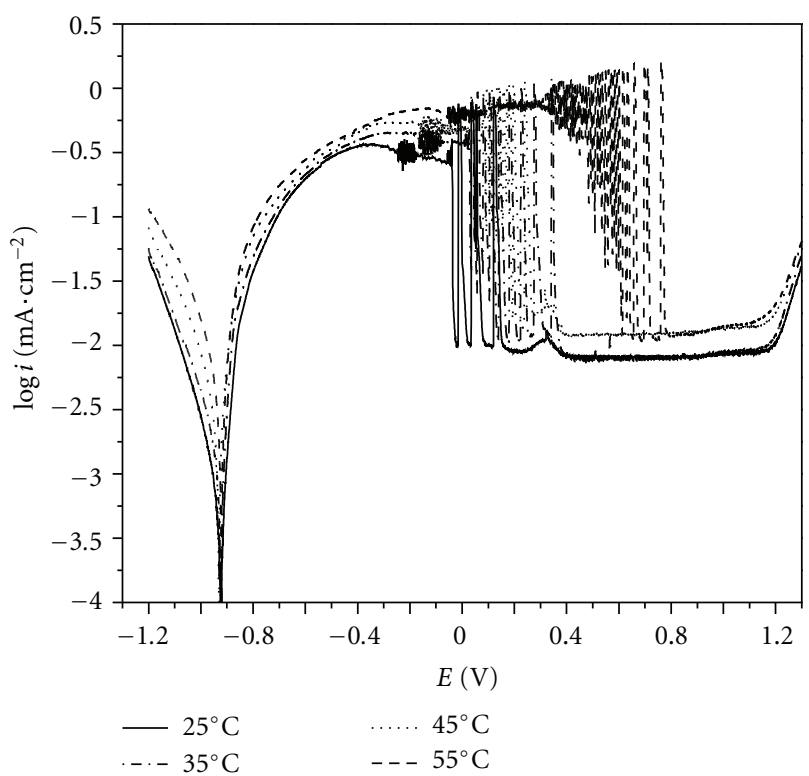

FIGURE 1: Potentiodynamic polarization curves at different temperatures.

The main observations which stand out from the anodic domain are the following ones: (i) the rise of temperature leads in a general way to the translation of the anodic curves towards more important values of current densities; (ii) in the neighbourhood of the corrosion potential, the anodic curves are very close; the effect of temperature is not that very remarkable (the anodic dissolution of the alloy is only weakly affected by the increase of temperature); (iii) otherwise, the formation of the anodic peak becomes less and less easy with the temperature rise, indicating the difficulty that the ferrous salt has to its formation; (iv) the potential range corresponding to the first zone of current oscillations (cycle of instability formation dissolution of the film) extends when the temperature increases from 25 to $55^{\circ} \mathrm{C}$; (v) the domain of the second (aperiodic) oscillations widens until joins the first package of oscillations at 45 and $55^{\circ} \mathrm{C}$; besides their amplitude rises with the increase of the temperature; (vi) this phenomenon leads to the decrease of the extent of the passivation plateau, because the rise of temperature delays the formation of the passive film; (vii) on the other hand, the value of the limit current density did not record an important variation according to the temperature; this confirms the stability of the formed film on the Fe-3Ti-2C surface; (viii) the transpassivation takes place in the same potential, whatever the temperature is.

The electrochemical parameters obtained from the polarization curves plots for Fe-3Ti-2C alloy in $1 \mathrm{~N}$ sulphuric acid are given in Table 1 . This includes the corrosion potential $\left(E_{\text {corr }}\right)$, anodic and cathodic Tafel slopes $\left(b_{a}\right.$ and $\left.b_{c}\right)$, and corrosion current density $\left(I_{\text {corr }}\right)$.

As expected, the corrosion current density of the ternary alloy is temperature dependent; indeed it is shifted to high values when temperature increases. However, the $E_{\text {corr }}$ values are nearly constant with temperature variation. 
TABLE 1: Electrochemical parameters deduced from the Tafel method at different temperatures.

\begin{tabular}{lcccc}
\hline $\begin{array}{l}T \\
\left({ }^{\circ} \mathrm{C}\right)\end{array}$ & $\begin{array}{l}E_{\text {corr }} \\
(\mathrm{mV})\end{array}$ & $\begin{array}{c}i_{\text {corr }} \\
\left(\mathrm{mA} \cdot \mathrm{cm}^{-2}\right)\end{array}$ & $\begin{array}{c}b_{a} \\
(\mathrm{mV} / \mathrm{dec})\end{array}$ & $\begin{array}{c}b_{c} \\
(\mathrm{mV} / \mathrm{dec})\end{array}$ \\
\hline 25 & -923 & 0.73 & 48 & -130 \\
35 & -924 & 1.40 & 48 & -156 \\
45 & -932 & 3.37 & 73 & -161 \\
55 & -923 & 5.36 & 78 & -164 \\
\hline
\end{tabular}

3.1.2. Linear Polarization Resistance Method. In this section we present only the electrochemical parameters deduced from the linear polarization method (Table 2) at various temperatures.

3.1.3. Electrochemical Impedance Spectroscopy. The temperature effect on Nyquist and Bode representations of the impedance values of the annealed alloy $\mathrm{Fe}-3 \mathrm{Ti}-2 \mathrm{C}$ in $1 \mathrm{~N}$ sulphuric acid are shown in Figure 2. The presence of a single capacitive semicircle in the complex plan and one constant time in Bode plan indicate that the corrosion of the alloy is controlled by charge transfer process, which is unaffected by the temperature increase. It can be seen that the circle diameter decreases when the temperature rises, and this is assigned to the metallic dissolution. The slightly depressed nature of the semicircle, that has the centre below the $x$-axis, is the characteristic of solid electrodes. Such frequency dispersion has been attributed to roughness and other heterogeneities of the solid electrode $[26,27]$.

The charge transfer resistance $\left(R_{t}\right)$ and the interfacial double layer capacitance $\left(C_{\mathrm{dl}}\right)$ values were derived by using the equivalent circuit modelled by the well-known iron-acid interface [28]; these data are given in Table 3. The analysis of the temperature effect, on charge transfer resistance $\left(R_{t}\right)$ of the alloy reveals that the highest is the temperature value, the lowest is the $\left(R_{t}\right)$ value, and consequently, the corrosion resistance of the metal decreases. However, the $C_{\mathrm{dl}}$ values are less affected by the temperature increase; this means that the corrosion products do not change the double layer structure [29].

In conclusion, whatever the technique, the $i_{\text {corr }}$ value of the studied alloy in sulphuric acid solution increases with the temperature rise.

\subsection{Effect of the Sodium Dodecyl Benzene Sulfonate (SDBS)} as a Corrosion Inhibitor. Surface active agents also called surfactants are characterised by critical micelle concentration (CMC). Most of the physical and chemical properties of surfactant solutions undergo an abrupt variation at this concentration [24]. In practice, the surface tension, osmotic pressure, and electrical conductivity parameters are measured for the determination of the CMC [30]. In our case, the CMC of SDBS in $1 \mathrm{~N}$ sulphuric acid at $25^{\circ} \mathrm{C}$ has been determined in our previous paper [31] using electrical conductivity measurements. The CMC value was estimated to be $10^{-3} \mathrm{M}$. Three electrochemical techniques have been used
TABLE 2: Electrochemical parameters deduced from the linear polarization method at different temperatures.

\begin{tabular}{lcccc}
\hline $\begin{array}{l}T \\
\left({ }^{\circ} \mathrm{C}\right)\end{array}$ & $\begin{array}{l}E_{\text {corr }} \\
(\mathrm{mV})\end{array}$ & $\begin{array}{c}R_{p} \\
\left(\Omega \cdot \mathrm{cm}^{2}\right)\end{array}$ & $\begin{array}{c}i_{\text {corr }} \\
\left(\mathrm{mA} \cdot \mathrm{cm}^{-2}\right)\end{array}$ & $\begin{array}{c}B \\
(\mathrm{mV} / \mathrm{dec})\end{array}$ \\
\hline 25 & -924 & 26.35 & 0.58 & 15.24 \\
35 & -930 & 10.70 & 1.49 & 15.95 \\
45 & -930 & 6.92 & 3.15 & 21.83 \\
55 & -929 & 4.13 & 5.56 & 22.98 \\
\hline
\end{tabular}

TABLE 3: Electrochemical parameters deduced from the electrochemical impedance spectroscopy at different temperatures.

\begin{tabular}{lcccc}
\hline $\begin{array}{l}T \\
\left({ }^{\circ} \mathrm{C}\right)\end{array}$ & $\begin{array}{c}E_{\text {corr }} \\
(\mathrm{mV} / \mathrm{ESS})\end{array}$ & $\begin{array}{c}R_{t} \\
\left(\Omega \cdot \mathrm{cm}^{2}\right)\end{array}$ & $\begin{array}{c}C_{\mathrm{dl}} \\
\left(\mathrm{mF} \cdot \mathrm{cm}^{-2}\right)\end{array}$ & $\begin{array}{c}i_{\text {corr }} \\
\left(\mathrm{mA} \cdot \mathrm{cm}^{-2}\right)\end{array}$ \\
\hline 25 & -925 & 25.61 & 0.31 & 0.59 \\
35 & -935 & 13.38 & 0.33 & 1.19 \\
45 & -931 & 7.38 & 0.34 & 2.95 \\
55 & -930 & 4.74 & 0.37 & 4.84 \\
\hline
\end{tabular}

to study the anionic surfactant (SDBS) effect on the corrosion behaviour of the ternary alloy in sulphuric acid solution.

3.2.1. Potentiodynamic Polarization Curves at $25^{\circ} \mathrm{C}$. The global polarization curve of the iron alloy in $1 \mathrm{~N}$ sulphuric acid, in the absence and presence of various concentrations of SDBS, is given in Figure 3. The addition of SDBS does not affect the general shape of the cathodic polarization curves. However, the current densities are translated to the lowest values. We can deduce therefore that the hydrogen evolution reaction is slowed by the anionic surfactant and that acts as a cathodic inhibitor. On the other hand, all the curves coincide at the onset of anodic region, and they separate at the potential about $-750 \mathrm{mV}$; this indicates that SDBS isnot adsorbed on the metal surface in this potential range. Beyond the adsorption potential $(-750 \mathrm{mV})$, some modifications in the shape of the anodic curves and a decrease of the current densities can be seen. Indeed, as the concentration of SDBS increases from $10^{-3} \mathrm{M}$ to $2 \cdot 10^{-2} \mathrm{M}$, the anodic current densities are shifted to the lowest values. However, when the concentration reaches $4.10^{-2} \mathrm{M}$, the current density increases. We have noticed that, whatever the surfactant concentration, all the current oscillations that indicate a cyclic activation passivation of the alloy have disappeared, extending thus the passivation plateau. Although, the current perturbations have disappeared, in the presence of SDBS at $10^{-3} \mathrm{M}$ and $10^{-2} \mathrm{M}$, the current limit remains constant $\left(i_{\text {lim }}=\right.$ $7 \mathrm{~mA} / \mathrm{cm}^{-2}$ ), whereas its value is $0.86 \mathrm{~mA} / \mathrm{cm}^{-2}$ at $2.10^{-2} \mathrm{M}$.

The obtained results show that the SDBS is adsorbed on the anodic sites (constituted of ferritic matrix), and this adsorption facilitated a disappearance of the oscillation zones. Indeed, while blocking the actives sites (anodic), the SDBS slows down the passage of $\mathrm{Fe}^{2+}$ ions toward the solution and prevents the formation of the unsteady compounds as $\mathrm{FeSO}_{4} \cdot 7 \mathrm{H}_{2} \mathrm{O}, \mathrm{Fe}(\mathrm{OH})_{2}$, and $\mathrm{Fe}_{3} \mathrm{O}_{4}$ which are at the origin of the establishment of the oscillations. Besides, the adsorption 


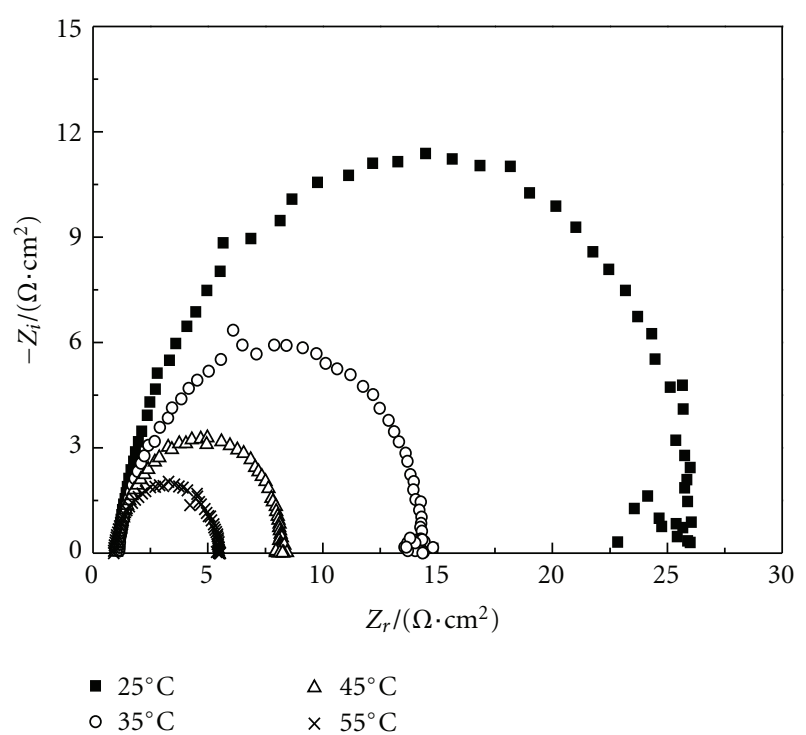

(a)

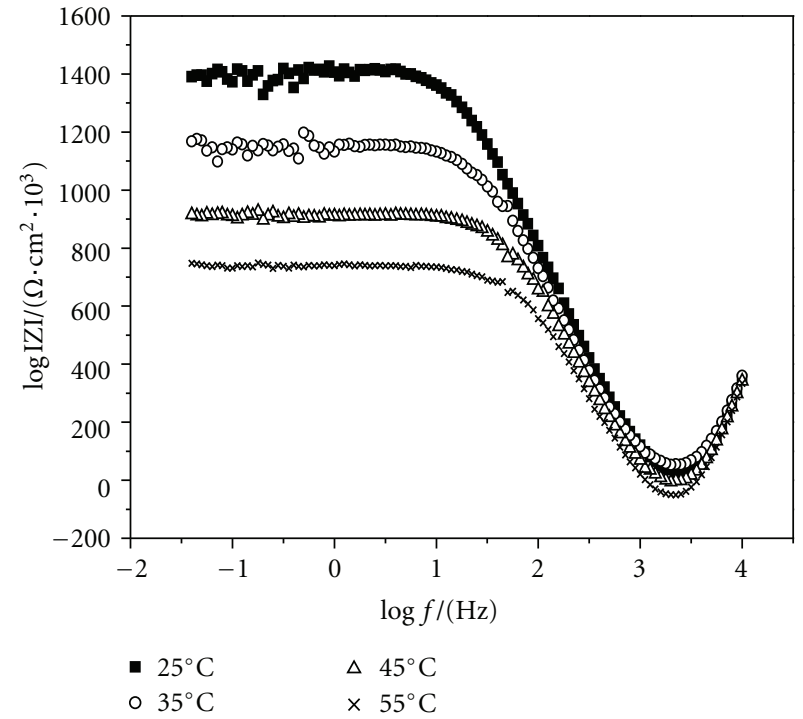

(b)

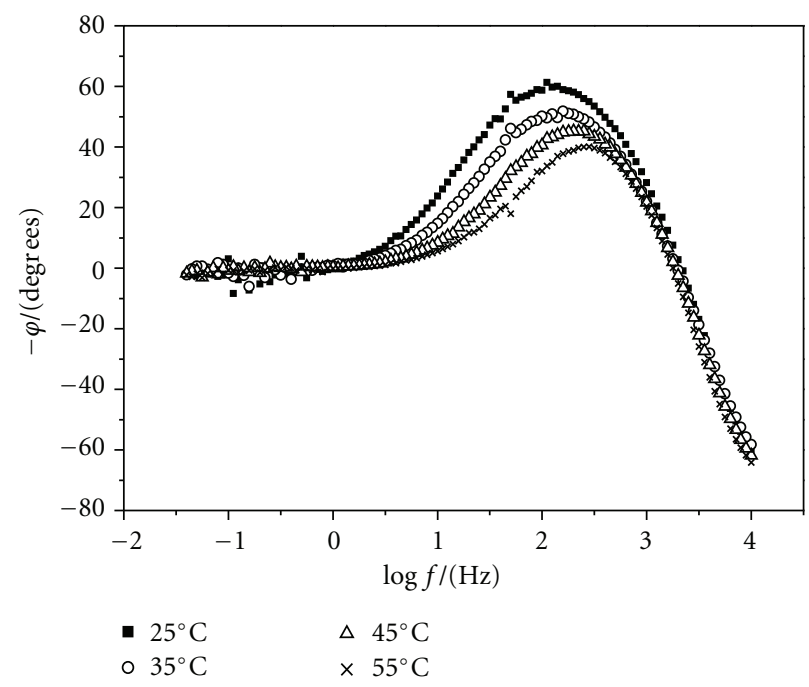

(c)

Figure 2: Temperature effect on (a) Nyquist, (b) Bode diagrams of the alloy in sulphuric acid.

of this surfactant allows consolidating the passive film by widening the passivation plateau.

Finally, we can say that the SDBS acts as a mixed inhibitor, because it acts as well on the cathodic as on the anodic current densities.

Table 4 collects the electrochemical parameters deduced by Tafel method. They are the corrosion potential $\left(E_{\text {corr }}\right)$, anodic and cathodic Tafel slopes $\left(b_{a}\right.$ and $\left.b_{c}\right)$, corrosion current density $\left(I_{\text {corr }}\right)$, inhibition efficiency $E(\%)$, and surface coverage $(\theta)$.

The percentage inhibition efficiency $(E \%)$ and surface coverage $(\theta)$ are obtained from the following relations:

$$
E \%=\left[\frac{\left(I_{0}-I\right)}{I_{0}}\right] \times 100,
$$

$$
\theta=\left[\frac{\left(I_{0}-I\right)}{I_{0}}\right]
$$

where $I_{0}$ and $I$ are the corrosion current densities obtained with and without SDBS, respectively.

As it can be seen from Table 4, the corrosion potential $\left(E_{\text {corr }}\right)$ has slightly shifted towards the cathodic potentials in presence of the different concentrations of SDBS. As the concentration of the inhibitor increases, the corrosion current density is reduced until reaching its lowest value at the concentration of $2.10^{-2} \mathrm{M}$, beyond which it starts again increasing. This phenomenon has been reported by other authors $[32,33]$ and attributed to the retreat of the surfactant from the metal-solution interface and its comeback toward the solution, after forming a bilayer structure constituted 


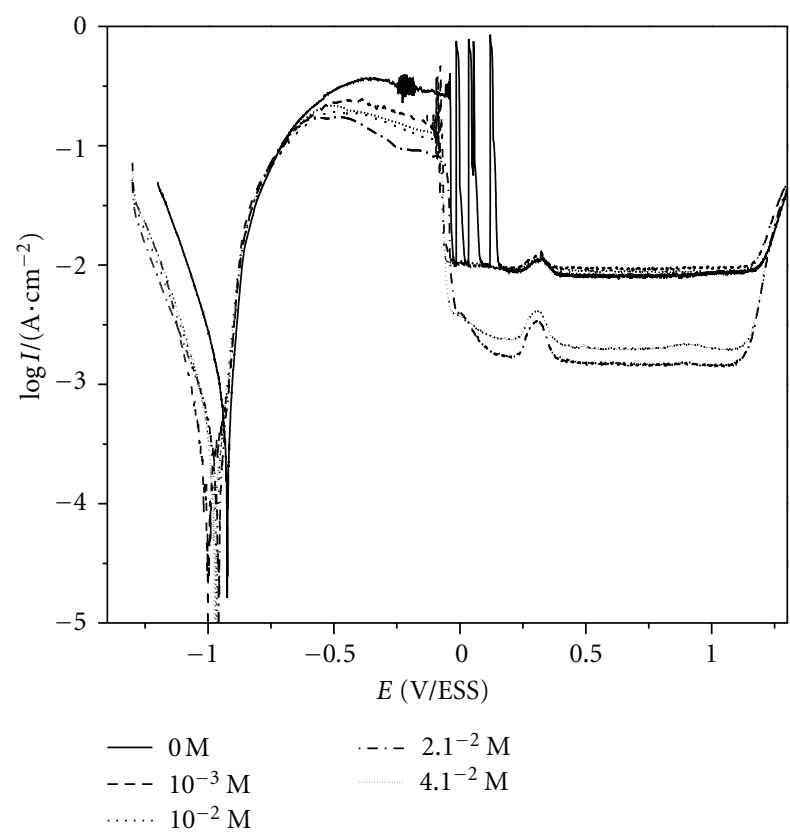

Figure 3: Polarization curves of iron alloy in $1 \mathrm{~N} \mathrm{H}_{2} \mathrm{SO}_{4}$ with different concentrations of SDBS at $25^{\circ} \mathrm{C}$.

by aggregates of hemimicelles. According to Atkins [34], a structure in monolayer is more stable than a structure in multilayer. The highest inhibition efficiency has been obtained at the concentration of $2.10^{-2} \mathrm{M}(84 \%)$; this concentration is superior to the CMC. It is well known that the inhibition efficiency increases with increasing surfactant concentration until it reaches a maximum value. This value corresponds to the CMC, and the inhibition efficiency of the metal slightly changes when the surfactant concentration exceeds the critical micelle concentration [19]. In our case, the highest inhibitor efficiency is obtained at a concentration above the CMC. This phenomenon is in agreement with the reported ones of Pebere et al. [35] and Fuchs-Godec [23]. We can suggest that the great number of the cathodic sites, constituted by titanium carbides $(\mathrm{TiC})$, needs a high concentration of SDBS to be blocked. This condition allows the suppression of the hydrogen evolution reaction (HER). On the other hand the surfactant adsorption on the anodic sites (ferritic phase) slows down all the metallic dissolution process modifying thus significantly the electrochemical behaviour of the iron alloy in the acidic solution.

3.2.2. AC Impedance Study at $25^{\circ} \mathrm{C}$. Figure 4 shows Nyquist and Bode plots of $\mathrm{Fe}-3 \mathrm{Ti}-2 \mathrm{C}$ immersed in normal sulphuric acid solution in presence of SDBS. As can be seen, the Nyquist plot in all cases appears as a depressed capacitive semicircle. Generally, the size of the diagrams increases with the concentration of the inhibitor (SDBS) indicating that a charge-transfer process mainly controls the corrosion of alloy. However, we noticed that at the concentration of $4.10^{-2} \mathrm{M}$ the semicircle diameter decreases.

From the impedance data (Table 5), we can see that the value of transfer charge resistance $R_{t}$ increases with
TABLE 4: Electrochemical parameters deduced by the Tafel method in $1 \mathrm{~N} \mathrm{H}_{2} \mathrm{SO}_{4}$ in the absence and presence of various concentrations of SDBS.

\begin{tabular}{lcccccc}
\hline $\begin{array}{l}\text { [SDBS }] \\
(\mathrm{mol} / \mathrm{L})\end{array}$ & $\begin{array}{c}E_{\text {corr }} \\
(\mathrm{mV})\end{array}$ & $\begin{array}{c}b_{a} \\
(\mathrm{mV} / \mathrm{dec})\end{array}$ & $\begin{array}{c}-b_{c} \\
(\mathrm{mV} / \mathrm{dec})\end{array}$ & $\begin{array}{c}I_{\text {corr }} \\
\left(\mathrm{mA} \cdot \mathrm{cm}^{-2}\right)\end{array}$ & $\% E$ & $\theta$ \\
\hline 0 & -923 & 48 & 130 & 0.73 & $/$ & $/$ \\
$10^{-3}$ & -1000 & 50 & 90 & 0.26 & 64 & 0.64 \\
$10^{-2}$ & -963 & 52 & 80 & 0.25 & 66 & 0.66 \\
$2 \cdot 10^{-2}$ & -959 & 40 & 60 & 0.12 & 84 & 0.84 \\
$4 \cdot 10^{-2}$ & -974 & 58 & 70 & 0.34 & 52 & 0.52 \\
\hline
\end{tabular}

TABLE 5: Electrochemical parameters deduced by EIS in the absence and presence of various concentrations of SDBS.

\begin{tabular}{lccccc}
\hline $\begin{array}{l}\text { [SDBS }] \\
(\mathrm{mol} / \mathrm{L})\end{array}$ & $\begin{array}{c}E_{\text {corr }} \\
(\mathrm{mV} / \mathrm{ESS})\end{array}$ & $\begin{array}{c}R_{t} \\
\left(\Omega \cdot \mathrm{cm}^{2}\right)\end{array}$ & $\begin{array}{c}C_{\mathrm{dl}} \\
\left(\mathrm{mF} \cdot \mathrm{cm}^{-2}\right)\end{array}$ & $\% E$ & $\theta$ \\
\hline 0 & -925 & 25.61 & 0.31 & $/$ & $/$ \\
$10^{-3}$ & -923 & 34.00 & 0.33 & 25 & 0.25 \\
$10^{-2}$ & -933 & 39.00 & 0.29 & 34 & 0.34 \\
$2 \cdot 10^{-2}$ & -957 & 69.00 & 0.25 & 63 & 0.63 \\
$4 \cdot 10^{-2}$ & -935 & 46.00 & 0.27 & 44 & 0.46 \\
\hline
\end{tabular}

increase in concentration of the inhibitor. On the other hand, the values of the double layer capacitance even they are brought down, there variation remains weak, probably that the addition of DBS does not modify the double layer structure.

The inhibition efficiency got from the charge-transfer resistance is calculated by

$$
\% E=\frac{1 / R_{t}^{0}-1 / R_{t}}{1 / R_{t}^{0}} \times 100 .
$$

$R_{t}^{0}$ and $R_{t}$ are the charge transfer resistance values without and with inhibitor, respectively.

It can be noticed that the maximum efficiency $(\% E)$ was obtained at the concentration of $2 \cdot 10^{-2} \mathrm{M}$ of SDBS, as already determined by the Tafel method.

3.2.3. Linear Polarization Technique. The corrosion current densities $\left(I_{\text {corr }}\right)$ are directly calculated from the polarization resistance $\left(R_{p}\right)$ [36]. The $R_{p}$ value can help us to assess the relative ability of a material to resist corrosion. Since $R_{p}$ is inversely proportional to $I_{\text {corr }}$, the materials with the highest $R_{p}$ (and thus the lowest $I_{\text {corr }}$ ) have the highest corrosion resistance. From all these facts, we can discuss and correlate between the data obtained from the $R_{p}$ and those computed from potentiodynamic polarization as well as impedance measurements.

The electrochemical parameters, namely, the polarisation resistance $\left(R_{p}\right)$, the corrosion current density $\left(I_{\text {corr }}\right)$, and the inhibition efficiency (Equation (2) has been used to determine the inhibition efficiency), are listed in Table 6.

It can be observed that the variation of the polarization resistance $\left(R_{p}\right)$ values is similar to the one of the chargetransfer resistance $\left(R_{t}\right)$, calculated from EIS method. Indeed, 


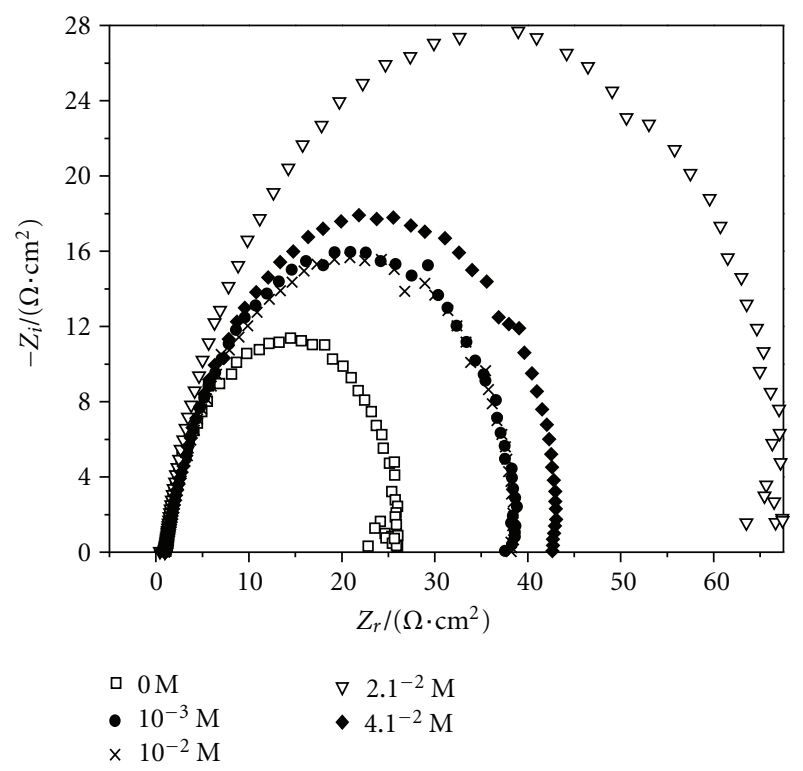

(a)

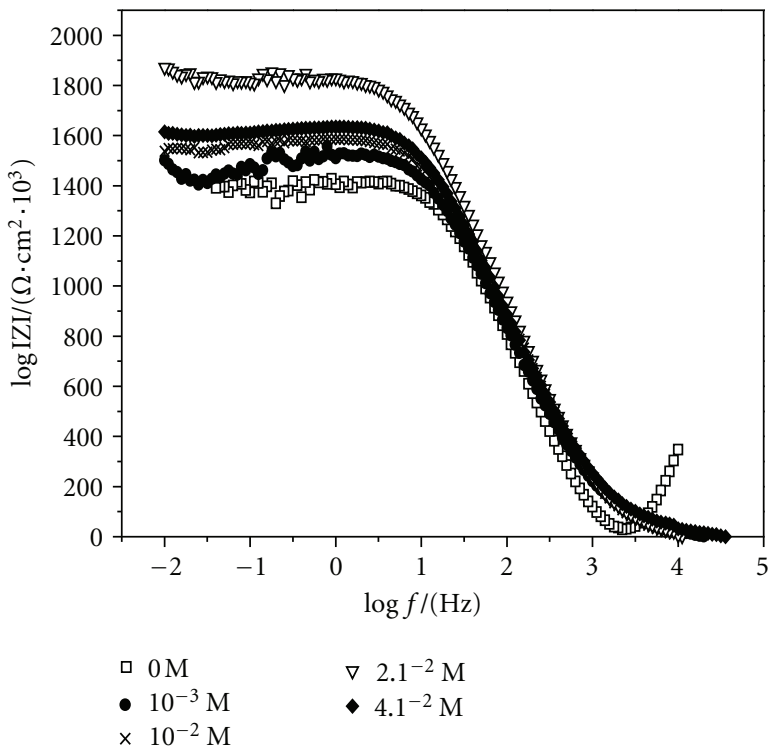

(b)

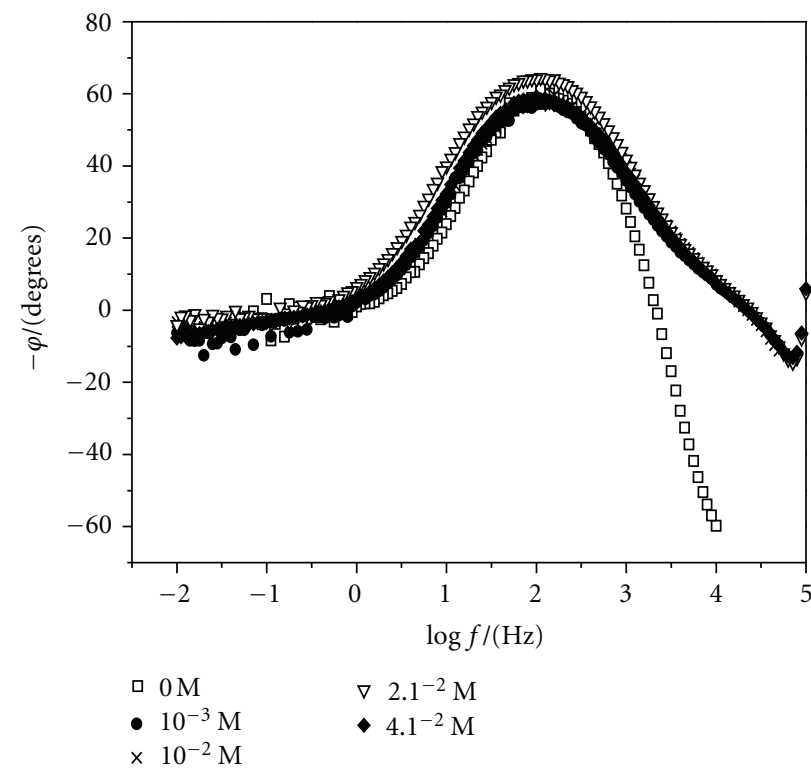

(c)

FIgURE 4: EIS diagrams in $1 \mathrm{~N} \mathrm{H}_{2} \mathrm{SO}_{4}$ at different concentrations of SDBS.

the highest value of $R_{p}\left(46 \Omega \cdot \mathrm{cm}^{2}\right)$ is obtained at the concentration of $2.10^{-2} \mathrm{M}$. On the other hand, the corrosion current densities $I_{\text {corr }}$ have the same evolution of those deduced by the Tafel method.

The results obtained by the three electrochemical techniques show that (i) SDBS does not affect significantly the corrosion potential; (ii) SDBS is really efficient only in the concentration of $2.10^{-2} \mathrm{M}$, that is, the optimal concentration; (iii) however, after its adsorption on the anodic sites (at $-750 \mathrm{mV}$ ), it reduces remarkably the anodic current densities, with removing the various oscillating states; (iv) the SDBS acts as a cathodic and anodic inhibitor; (v) the adsorption is a potential electrode dependent in the anodic potentials domain; (vi) the corrosion process is activation controlled and has not been affected by the presence of the anionic surfactant.

3.3. Temperature Effect in Presence of the SDBS at Its Optimal Concentration. The temperature can modify the interaction between the surface state of the working electrode and the acidic medium. The temperature effect on the potentiodynamic polarization curves for Fe-3Ti-2C alloy in $1 \mathrm{~N}$ sulphuric acid with $2.10^{-2} \mathrm{M}$ SDBS is shown in Figure 5. It can be shown that the parallel cathodic curves are translated towards the high values current densities as temperature rises 
TABLE 6: Electrochemical parameters deduced by linear polarization method in the absence and presence of various concentrations of SDBS.

\begin{tabular}{lcccccc}
\hline $\begin{array}{l}\text { [SDBS }] \\
(\mathrm{mol} / \mathrm{L})\end{array}$ & $\begin{array}{c}E_{\text {corr }} \\
(\mathrm{mV} / \mathrm{ESS})\end{array}$ & $\begin{array}{c}R_{p} \\
\left(\Omega \cdot \mathrm{cm}^{2}\right)\end{array}$ & $\begin{array}{c}B \\
(\mathrm{mV} / \mathrm{dec})\end{array}$ & $\begin{array}{c}I_{\text {corr }} \\
\left(\mathrm{mA} \cdot \mathrm{cm}^{-2}\right)\end{array}$ & $\% E$ & $\theta$ \\
\hline 0 & -924 & 26 & 15.24 & 0.57 & $/$ & $/$ \\
$1 \cdot 10^{-3}$ & -931 & 35 & 13.97 & 0.40 & 30 & 0.30 \\
$1 \cdot 10^{-2}$ & -834 & 37 & 13.70 & 0.37 & 35 & 0.35 \\
$2 \cdot 10^{-2}$ & -831 & 46 & 10.43 & 0.22 & 61 & 0.61 \\
$4 \cdot 10^{-2}$ & -935 & 41 & 13.79 & 0.33 & 42 & 0.42 \\
\hline
\end{tabular}

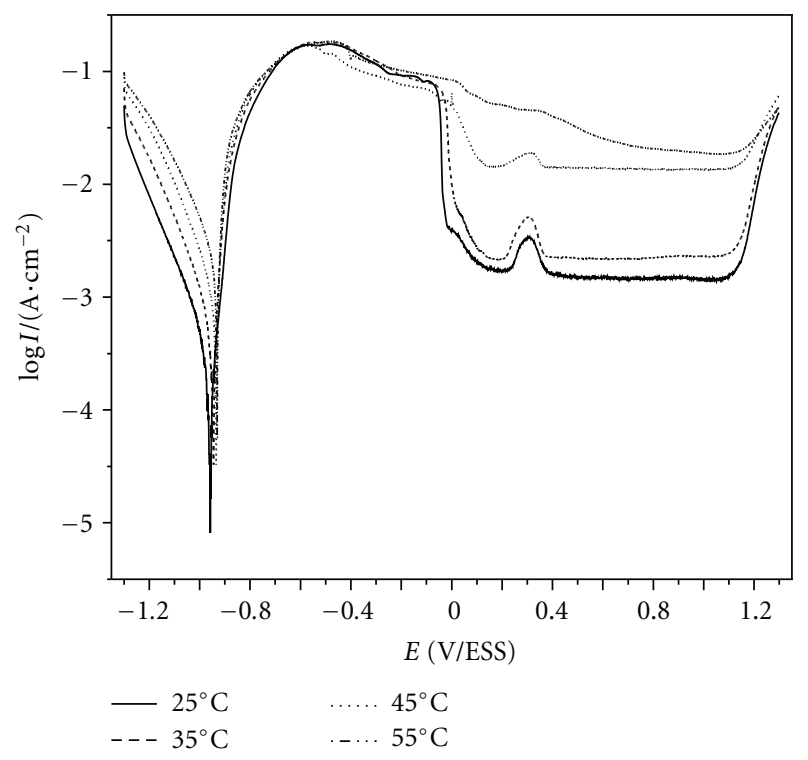

FIgURE 5: Temperature effect on the polarization curves at the optimal concentration of SDBS.

from $25^{\circ} \mathrm{C}$ to $55^{\circ} \mathrm{C}$. On the other hand, we observe in the low anodic overvoltages a slight translation of the curves to higher current densities, indicating that the temperature does not influence significantly the anodic dissolution of $3 \mathrm{Ti}$ in this range of potentials (from $E_{\text {corr }}$ up to approximately $-0.1 \mathrm{~V} / \mathrm{ESS}$ ). Beyond this potential zone the temperature effect is remarkable for two temperatures of $45^{\circ} \mathrm{C}$ and $55^{\circ} \mathrm{C}$.

Indeed, the limit current density $\left(i_{\text {lim }}\right)$ records a significant increase, indicating that the film formed on the metallic surface becomes less efficient. We deduce that a partial desorption of SDBS occurs at the potential of $0.1 \mathrm{~V}$, from the anodic sites. An interesting fact is noted: increasing the temperature does not favour the establishment of two types of oscillations observed in the absence of SDBS. Concerning the chaotic oscillations (close to the active zone), they do not appear because, in this range of potentials, the SDBS is adsorbed whatever the considered temperature, thereby slowing the diffusion of $\mathrm{Fe}^{2+}$ ions to the solution. As for the latter oscillations (those preceding the passivation plateau), they cannot settle, because the adsorption, even partial, of SDBS on the active sites (ferrite) prevents the occurring of the events of the oxide dissolution (cycle dissolution formation). All the points mentioned above lead us to deduce that the
TABLE 7: Temperature effect on the electrochemical parameters deduced by the Tafel method at the optimal concentration.

\begin{tabular}{lcccccc}
\hline $\begin{array}{l}T \\
\left({ }^{\circ} \mathrm{C}\right)\end{array}$ & $\begin{array}{c}E_{\text {corr }} \\
(\mathrm{mV} / \mathrm{ESS})\end{array}$ & $\begin{array}{c}b_{a} \\
(\mathrm{mV} / \mathrm{dec})\end{array}$ & $\begin{array}{c}-b_{c} \\
(\mathrm{mV} / \mathrm{dec})\end{array}$ & $\begin{array}{c}I_{\text {corr }} \\
\left(\mathrm{mA} \cdot \mathrm{cm}^{-2}\right)\end{array}$ & $\% E$ & $\theta$ \\
\hline $25^{\circ} \mathrm{C}$ & -959 & 40 & 60 & 0.12 & 84 & 0.84 \\
$35^{\circ} \mathrm{C}$ & -954 & 40 & 140 & 0.54 & 61.43 & 0.61 \\
$45^{\circ} \mathrm{C}$ & -934 & 39 & 167 & 1.34 & 60.23 & 0.60 \\
$55^{\circ} \mathrm{C}$ & -930 & 60 & 196 & 2.18 & 59.33 & 0.59 \\
\hline
\end{tabular}

mechanism of dissolution of the ferrous alloy is under control of a pure activation regime, whatever the temperature studied, and only the kinetics of proton discharge is accelerated by increasing temperature. Furthermore, the adsorption of the DBS on the anodic sites is indifferent to the temperature variation in the potential range from $0.750 \mathrm{~V}$ at $0.1 \mathrm{~V}$. This adsorption was effective, even beyond this value, since it has eliminated the active states occurring during the different oscillations.

The various electrochemical parameters are collected in Table 7, inferred from the Tafel method.

In view of the obtained results, it emerges that the corrosion current density $\left(I_{\text {corr }}\right)$ grows under the influence of the rise in temperature. Consequently, the inhibition efficiency $(E)$ is reduced under the effect of temperature, thereby decreasing the performance of the alloy, in the considered environment, although it remains effective at all temperatures, because its inhibition efficiency exceeds $50 \%$.

Arrhenius plots for the corrosion current density of $\mathrm{Fe}$ $3 \mathrm{Ti}-2 \mathrm{C}$ are depicted in Figure 6. The activation energies can be calculated from the following set of equations:

$$
\begin{aligned}
& I_{\text {corr }}=K \exp \left(-\frac{E_{a}}{R_{T}}\right), \\
& I_{\text {corr }}^{\prime}=K \exp \left(-\frac{E_{a}^{\prime}}{R_{T}}\right),
\end{aligned}
$$

where $E_{a}$ and $E_{a}^{\prime}$ are the activation corrosion energies in the absence and presence of the inhibitor, respectively. $T$ is the absolute temperature, $K$ is the Arrhenius preexponential constant, and $R$ is the universal gas constant.

The calculated values of apparent activation energy are: $E_{a}=56.85 \mathrm{~kJ} \cdot \mathrm{mol}^{-1}$ and $E_{a}^{\prime}=79.43 \mathrm{~kJ} \cdot \mathrm{mol}^{-1}$. The activation energy of the blank solution is comparable with that reported by many investigations $[1,4]$ for ferrous alloys in $\mathrm{H}_{2} \mathrm{SO}_{4}$ solution. The results clearly show that the inhibited solution has high value of $E_{a}$ than that of the uninhibited one. This enhancing of $E_{a}$ in the presence of the inhibitor indicates that more energy barrier for the corrosion reaction in presence of the surfactant SDBS is attained [19]. The rising in activation energy value, when compared to the blank solution, suggested that there is a reduction in corrosion rate [37]. This phenomenon is generally interpreted as an indication for the formation of an adsorptive film. This fact is governed by a physical (electrostatic) mechanism or a weak chemical bonding between the inhibitor molecules and the metal surface [22]. 
TABLE 8: Temperature effect on the electrochemical parameters deduced from EIS.

\begin{tabular}{lccccc}
\hline $\begin{array}{l}\mathrm{T} \\
\left({ }^{\circ} \mathrm{C}\right)\end{array}$ & $\begin{array}{c}E_{\text {corr }} \\
(\mathrm{mV} / \mathrm{ESS})\end{array}$ & $\begin{array}{c}R_{t} \\
\left(\Omega \cdot \mathrm{cm}^{2}\right)\end{array}$ & $\begin{array}{c}C_{\mathrm{dl}} \\
\left(\mathrm{mF} \cdot \mathrm{cm}^{-2}\right)\end{array}$ & $\% E$ & $\theta$ \\
\hline $25^{\circ} \mathrm{C}$ & -957 & 69.00 & 0.258 & 63 & 0.63 \\
$35^{\circ} \mathrm{C}$ & -937 & 24.00 & 0.294 & 44 & 0.44 \\
$45^{\circ} \mathrm{C}$ & -947 & 11.52 & 0.345 & 36 & 0.36 \\
$55^{\circ} \mathrm{C}$ & -942 & 07.26 & 0.346 & 35 & 0.35 \\
\hline
\end{tabular}

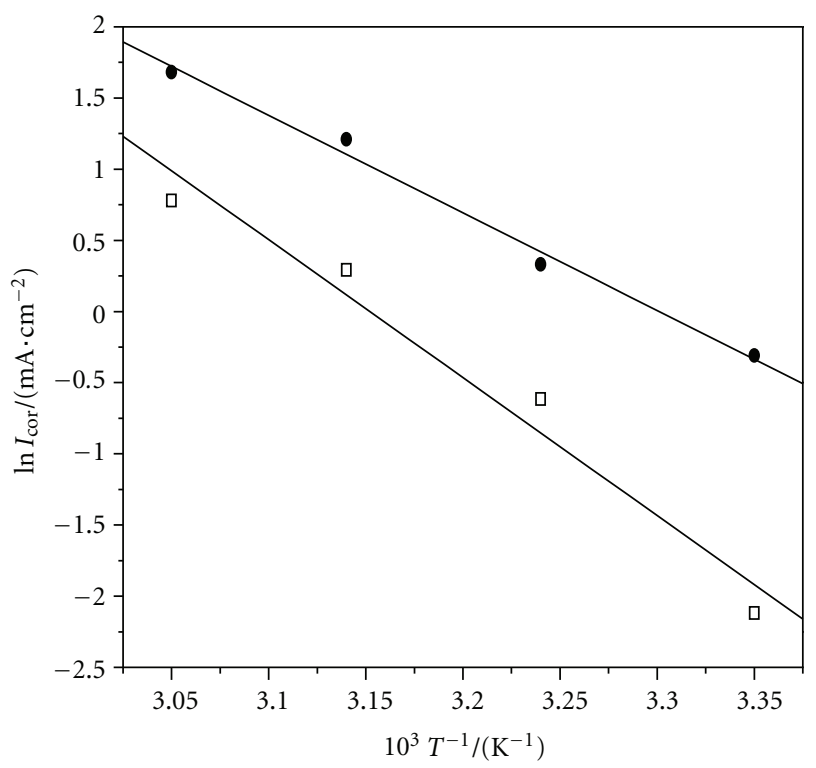

$\square$ With DBS

- Without DBS

FIGURE 6: Arrhenius plots calculated from corrosion current densities deduced from the Tafel method.

The impedance diagrams plotted in the plans Nyquist and Bode for the Fe-3Ti-2C immersed in the inhibitor solution at various temperatures are shown in Figure 7. Examination of the latter reveals that, whatever the temperature considered, the impedance diagram consists of a single capacitive loop, whose diameter decreases with temperature. This phenomenon translates the reduction of the inhibitive efficiency of the SDBS towards the corrosion of the Fe-3Ti$2 \mathrm{C}$ in $1 \mathrm{~N}$ sulphuric acid. This is confirmed by the diagram of Bode (Figure 7) which shows a decrease of the impedance modulus $(|Z|)$ and phase angle $(\varphi)$.

The impedance parameters are given in Table 8 . It is noteworthy that the resistance values of charge transfer $\left(R_{t}\right)$, reflecting a decrease in the temperature range studied. In contrast, the values of double layer capacity $\left(C_{\mathrm{dl}}\right)$ did not suffer a remarkable increase: the temperature does not seem to markedly affect the structure of the double layer (at the metal-solution interface).

The values of inhibition efficiency are lessening in the temperature range considered. We note that these values, although even tending as those collected by the Tafel method,
TABLE 9: Temperature influence on the electrochemical parameters deduced from linear polarization technique.

\begin{tabular}{lcccccc}
\hline $\begin{array}{l}T \\
\left({ }^{\circ} \mathrm{C}\right)\end{array}$ & $\begin{array}{c}E_{\text {corr }} \\
(\mathrm{mV} / \mathrm{ESS})\end{array}$ & $\begin{array}{c}R_{p} \\
\left(\Omega \cdot \mathrm{cm}^{2}\right)\end{array}$ & $\begin{array}{c}B \\
(\mathrm{mV} / \mathrm{dec})\end{array}$ & $\begin{array}{c}I_{\text {corr }} \\
\left(\mathrm{mA} \cdot \mathrm{cm}^{-2}\right)\end{array}$ & $\% E$ & $\theta$ \\
\hline 25 & -931 & 46.00 & 10.43 & 0.22 & 61 & 0.61 \\
35 & -936 & 22.00 & 13.52 & 0.62 & 58 & 0.58 \\
45 & -841 & 09.54 & 13.74 & 1.44 & 54 & 0.54 \\
55 & -838 & 07.47 & 19.97 & 2.67 & 52 & 0.52 \\
\hline
\end{tabular}

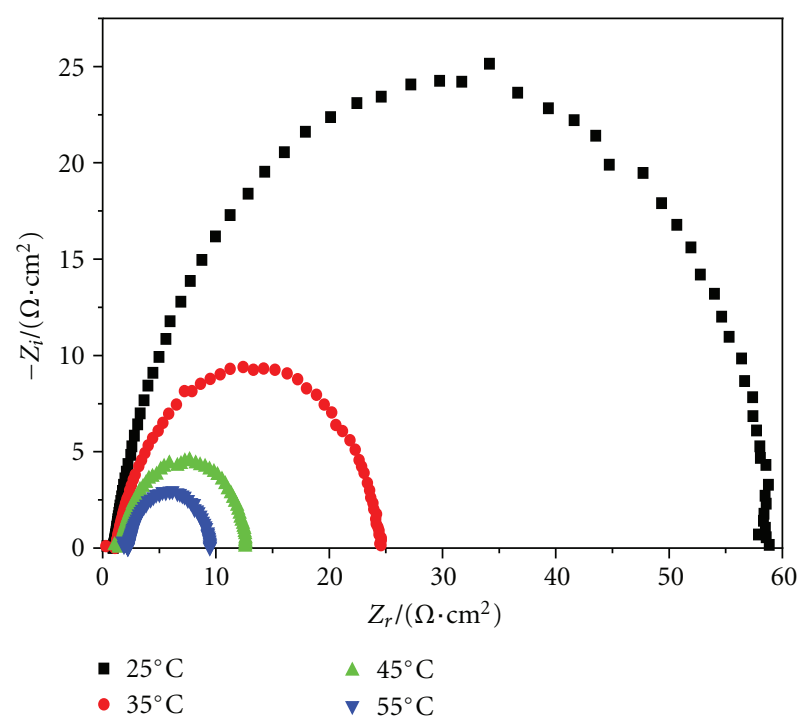

FIGURE 7: Effect of temperature on the impedance diagrams.

are lower. All these results show a decline in the performance of surfactant, at high temperatures.

The results obtained using linear polarization curves for the Fe-3Ti-2C in sulphuric acid solution in the presence of SDBS at various temperatures are summarized in Table 9. Analysis of the collected data reflects a decrease of polarization resistance $\left(R_{p}\right)$ in the temperature range studied. The opposite effect is observed for corrosion current densities $\left(I_{\text {cor }}\right)$, leading to a decrease of the inhibition efficiency $(\% E)$.

These results are in accordance with those obtained by the techniques of the Tafel and EIS; they so come to confirm that SDBS loses partially its inhibitive efficiency at high temperatures, due to its desorption from the cathodic sites.

3.3.1. Adsorption Isotherm. To determine the adsorption process, the values of surface coverage $\theta$ obtained from Tafel method, corresponding to different concentrations of SDBS at $25^{\circ} \mathrm{C}$, were used to explain the best isotherm. The adsorption of an organic compound at a metal-solution interface can be represented as a substitutional adsorption process between the organic molecules in the aqueous solution $\mathrm{Org}_{(\mathrm{sol})}$ and the water molecules on the metallic surface $\mathrm{H}_{2} \mathrm{O}_{(\text {ads })}$ [38]:

$$
\mathrm{AS}_{(\mathrm{sol})}+x \mathrm{H}_{2} \mathrm{O}_{(\mathrm{ads})} \longrightarrow \mathrm{AS}_{(\mathrm{ads})}+x \mathrm{H}_{2} \mathrm{O}_{(\mathrm{sol})} \text {, }
$$

where $\mathrm{AS}_{(\text {sol })}$ and $\mathrm{AS}_{(\text {ads })}$ are the surfactant molecules in the acidic solution and are adsorbed on metallic surface, 


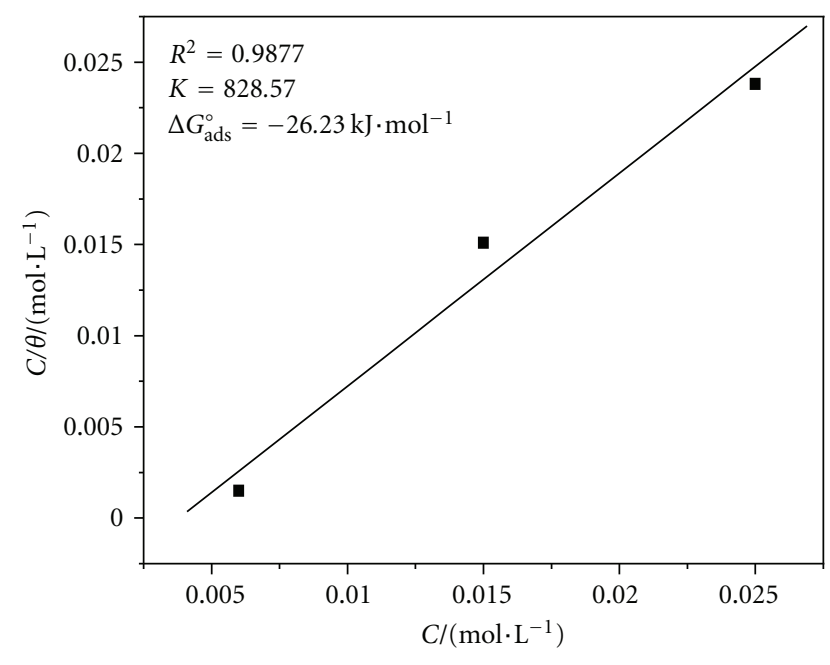

FIGURE 8: Langmuir adsorption isotherm in the presence of SDBS.

respectively. $\mathrm{H}_{2} \mathrm{O}_{(\text {ads })}$ is the water molecule adsorbed on the metallic surface, and $x$ is the size ratio representing number of water molecules replaced by one molecule of surfactant adsorbate. Several attempts were made to identify among all the adsorption isotherms the one which presents the best correlation with our experimental points. The use of the values of surface coverage $\theta$, deducted from the Tafel method, allowed us to express the most suitable isotherm. We, therefore, selected the Langmuir isotherm equation, which is given as [39]

$$
\frac{C}{\theta}=\frac{1}{K}+C
$$

where $\theta$ is the surface coverage degree, $K$ the equilibrium constant of the adsorption process, and $C$ the inhibitor concentration in $1 \mathrm{~N}$ sulphuric acid. The constant $K$ is related to the standard free energy of adsorption $\left(\Delta G_{\text {ads }}^{\circ}\right)$ by

$$
K=\frac{1}{55.5} \exp \left(-\frac{\Delta G_{\mathrm{ads}}^{\circ}}{R_{T}}\right) .
$$

The value of 55.5 is the concentration of water in solution expressed in mol.

Figure 8 illustrates the Langmuir isotherm obtained by the plot of $C / \theta$ according to $C$. The graph is represented by a right, the correlation coefficient of which is 0.987 .

By analyzing the equation of the obtained right, we notice that the slope $(n=1.16)$ is slightly superior to the unity, this phenomenon has been reported by several studies [12, $40,41]$, and it was attributed to interactions between the organic molecules, adsorbed on the metallic surface [42]. It corresponds to the number of sites occupied by every molecule of surfactant adsorbed on the metal surface [40].

Recently, Arab [12] attributed the deviation from ideality $(n=1)$ to the adsorption of molecules with polar groups, on the anodic and cathodic sites of the corroded surface. The adsorbed species can interacted with each other by repulsive or attractive strengths. The equation relative to the model modified by Langmuir is therefore more appropriate to model at best the adsorption of molecules at the interface of metal solution:

$$
\frac{C}{\theta}=\frac{n}{K}+n C,
$$

where " $n$ " is the number of the actives sites.

The negative value of $\Delta G_{\text {ads }}^{\circ}\left(-26,34 \mathrm{~kJ} \cdot \mathrm{mol}^{-1}\right)$ indicates that the SDBS is spontaneously adsorbed on the surface of the alloy. This value of $\Delta G_{\text {ads }}^{\circ}$ is slightly lower than $-20 \mathrm{~kJ} \cdot \mathrm{mol}^{-1}$, and this is significant of electrostatic interactions between molecules charged negatively of the surfactant and the positive charge [43] of the metal (physical adsorption).

\section{Conclusion}

This study reveals that the increase of the temperature from $25^{\circ} \mathrm{C}$ at $55^{\circ} \mathrm{C}$ accelerates the dissolution of the ferrous alloy in the $1 \mathrm{~N}$ sulphuric acid solution.

Considering the obtained results, we can summarize the effect of the DBS on the electrochemical behavior of Fe-3Ti$2 \mathrm{C}$ immersed in a normal solution of sulphuric acid in several points quoted below.

(i) The SDBS adsorbs on the cathodic sites, slowing down the reaction of the proton discharge it reduces of this fact the corrosion rate of the alloy, it can be considered as cathodic inhibitor.

(ii) All the current oscillations are inhibited by the adsorption of the SDBS on the active sites (ferrite); it acts therefore as anodic inihbitor.

(iii) The adsorption of SDBS on the ternary alloy surface in normal sulphuric acid obeys the Langmuir adsorption isotherm model. The SDBS inhibits the corrosion of Fe-3Ti-2C in the acidic solution by physisorption on the cathodic sites as well as the anodic ones.

\section{References}

[1] A. S. Algaber, E. M. El-Nemma, and M. M. Saleh, "Effect of octylphenol polyethylene oxide on the corrosion inhibition of steel in $0.5 \mathrm{M} \mathrm{H}_{2} \mathrm{SO}_{4}$," Materials Chemistry and Physics, vol. 86, no. 1, pp. 26-32, 2004.

[2] T. Y. Soror and M. A. El-Ziady, Materials Chemistry and Physics, vol. 77, p. 97, 2002.

[3] F. Bentiss, M. Lagrenee, M. Traisnel, and J. C. Hornez, "Corrosion inhibition of mild steel in $1 \mathrm{~m}$ hydrochloric acid by 2,5bis(2-aminophenyl)-1,3,4-oxadiazole," Corrosion, vol. 55, no. 10, pp. 968-976, 1999.

[4] G. Moretti, G. Quartarone, A. Tassan, and A. Zingales, "5amino- and 5-chloro-indole as mild steel corrosion inhibitors in in sulphuric acid," Electrochimica Acta, vol. 41, no. 13, pp. 1971-1980, 1996

[5] F. Bentiss, M. Traisnel, and M. Lagrenee, "Influence of 2,5-bis(4dimethylaminophenyl)-1,3,4-thiadiazole on corrosion inhibition of mild steel in acidic media," Journal of Applied Electrochemistry, vol. 31, no. 1, pp. 41-48, 2001.

[6] K. F. Khaled and N. Hackerman, "Investigation of the inhibitive effect of ortho-substituted anilines on corrosion of iron in 0.5 
$\mathrm{M} \mathrm{H}_{2} \mathrm{SO}_{4}$ solutions," Materials Chemistry and Physics, vol. 82, pp. 949-960, 2003.

[7] M. Bouklah, B. Hammouti, M. Benkaddour, and T. Benhadda, "Thiophene derivatives as effective inhibitors for the corrosion of steel in $0.5 \mathrm{M} \mathrm{H}_{2} \mathrm{SO}_{4}$," Journal of Applied Electrochemistry, vol. 35, pp. 1095-1101, 2005.

[8] M. M. Saleh, "Inhibition of mild steel corrosion by hexadecylpyridinium bromide in $0.5 \mathrm{M} \mathrm{H}_{2} \mathrm{SO}_{4}$," Materials Chemistry and Physics, vol. 98, pp. 83-89, 2006.

[9] H. Ma, T. Song, H. Sun, and X. Li, "Experimental and theoretical elucidation on the inhibition mechanism of 1-methyl-5mercapto-1,2,3,4-tetrazole self-assembled films on corrosion of iron in $0.5 \mathrm{M} \mathrm{H}_{2} \mathrm{SO}_{4}$," Thin Solid Films, vol. 516, pp. 1020-1024, 2008.

[10] B. Gao, X. Zhang, and Y. Sheng, Materials Chemistry and Physics, vol. 108, p. 375, 2008.

[11] P. Bothi Raja and M. G. Sethuraman, "Atropine sulphate as corrosion inhibitor for mild steel in sulphuric acid medium," Materials Letters, vol. 62, no. 10-11, pp. 1602-1604, 2008.

[12] S. T. Arab, "Inhibition action of thiosemicabazone and some of it is $\rho$-substituted compounds on the corrosion of iron-base metallic glass alloy in $0.5 \mathrm{M} \mathrm{H}_{2} \mathrm{SO}_{4}$ at $30^{\circ} \mathrm{C}$," Materials Research Bulletin, vol. 43, no. 3, pp. 510-521, 2008.

[13] S. A. Umoren, Y. Li, and F. H. Wang, "Influence of aluminium microstructure on corrosion and corrosion inhibitor performance in acidic medium," Journal of Materials and Environmental Science, vol. 1, no. 3, pp. 189-196, 2010.

[14] C. A. Loto, "Inhibition effect of Tea (Camellia Sinensis) extract on the corrosion of mild steel in dilute sulphuric acid," Journal of Materials and Environmental Science, vol. 2, pp. 335-344, 2011.

[15] R. Zhang and P. Somasundaran, "Advances in adsorption of surfactants and their mixtures at solid/solution interfaces," Advances in Colloid and Interface Science, vol. 123, pp. 213-229, 2006.

[16] M. Elachouri, M. S. Hajji, M. Salem et al., "Some nonionic surfactants as inhibitors of the corrosion of iron in acid chloride solutions," Corrosion, vol. 52, no. 2, pp. 103-108, 1996.

[17] P. Manjula, S. Manonmani, P. Jayaram, and S. Rajendran, "Corrosion behaviour of carbon steel in the presence of $\mathrm{N}$ cetyl-N,N,N-trimethylammonium bromide, $\mathrm{Zn} 2+$ and calcium gluconate," Anti-Corrosion Methods and Materials, vol. 48, no. 5, pp. 319-323, 2001.

[18] C. Jeyprabha, S. Sathiyanarayanan, and G. Venkatachari, Applied Surface Science, vol. 246, p. 108, 2005.

[19] M. A. Deyab, "Effect of cationic surfactant and inorganic anions on the electrochemical behavior of carbon steel in formation water," Corrosion Science, vol. 49, pp. 2315-2328, 2007.

[20] M. Z. A. Rafiquee, N. Saxena, S. Khan, and M. A. Quraishi, "Influence of surfactants on the corrosion inhibition behaviour of 2-aminophenyl-5-mercapto-1-oxa-3,4-diazole (AMOD) on mild steel," Materials Chemistry and Physics, vol. 107, no. 2-3, pp. 528-533, 2008.

[21] A. Zarrouk, H. Zarrok, R. Salghi et al., "Evaluation of Ncontaining organic compound as corrosion inhibitor for carbon steel in phosphoric acid," Journal of Materials and Environmental Science, vol. 4, pp. 177-192, 2013.

[22] M. Bouklah, N. Benchat, A. Aounit et al., Progress in Organic Coatings, vol. 51, p. 118, 2004.
[23] R. Fuchs-Godec, "The adsorption, CMC determination and corrosion inhibition of some $\mathrm{N}$-alkyl quaternary ammonium salts on carbon steel surface in $2 \mathrm{M} \mathrm{H}_{2} \mathrm{SO}_{4}$," Colloids and Surfaces A, vol. 280, no. 1-3, pp. 130-139, 2006.

[24] F. Kellou, A. Benchettara, and S. Amara, "Temperature and microstructure effects on corrosion behavior of annealed FexTi-yC alloys in sulphuric acid solution," Materials Chemistry and Physics, vol. 106, no. 2-3, pp. 198-208, 2007.

[25] T. Tsuru, S. Huruyama, and B. Gjutsu, Journal of Japan Society of Corrosion Engineering, vol. 27, p. 573, 1978.

[26] W. Scheider, J.Phys.Chem, vol. 79, 127 pages, 1975.

[27] T. Pajkossy, "Impedance of rough capacitive electrodes," Journal of Electroanalytical Chemistry, vol. 364, pp. 111-125, 1994.

[28] F. Mansfeld, M. W. Kendig, and W. J. Lorenz, "Corrosion inhibition in neutral, aerated media," Journal of The Electrochemical Society, vol. 132, p. 290, 1985.

[29] A. Bonnel, F. Dabosi, C. Deslouis, M. Dupart, M. Keddam, and B. Trabolet, Journal of The Electrochemical Society, vol. 130, 573 pages, 1983.

[30] D. J. Shaw, Introduction to Colloids and Surface Chemistry, Butterworth and Co, London, UK, 1978.

[31] F. Kellou-Kerkouche, A. Benchettara, and S. Amara, "Effect of sodium dodecyl benzene sulfonate on the corrosion inhibition of Fe-1Ti-20C alloy in $0.5 \mathrm{M} \mathrm{H}_{2} \mathrm{SO}_{4}$," Materials Chemistry and Physics, vol. 110, no. 1, pp. 26-33, 2008.

[32] S. T. Keera and M. A. Deyab, "Effect of some organic surfactants on the electrochemical behaviour of carbon steel in formation water," Colloids and Surfaces A, vol. 266, no. 1-3, pp. 129-140, 2005.

[33] M. Hosseini, S. F. L. Mertens, and M. R. Arshadi, "Synergism and antagonism in mild steel corrosion inhibition by sodium dodecylbenzenesulphonate and hexamethylenetetramine," Corrosion Science, vol. 45, no. 7, pp. 1473-1489, 2003.

[34] P. W. Atkins, “Chimie Physique," traduction de la 6ème édition, chapter 23 et 24, 1998.

[35] N. Pebere, M. Duprat, F. Dabosi, A. Lattes, and A. De Savignac, "Corrosion inhibition study of a carbon steel in acidic media containing hydrogen sulphide and organic surfactants," Journal of Applied Electrochemistry, vol. 18, no. 2, pp. 225-231, 1988.

[36] M. Stern and A. L. Geary, "A theoretical analysis of the shape of polarization curves," Journal of The Electrochemical Society, vol. 104, pp. 56-63, 1957.

[37] M. Ramananda Singh, "A green Approach: a corrosion inhibition of mild steel by adhatoda vasica plant extract in $0.5 \mathrm{M}$ $\mathrm{H}_{2} \mathrm{SO}_{4}$," Journal of Materials and Environmental Science, vol. 4, pp. 117-126, 2013.

[38] G. Moretti, G. Quartarone, A. Tassan, and A. Zingales, Werkstoffe und Korrosion, vol. 45, p. 641, 1994.

[39] R. F. V. Villamil, P. Corio, S. M. L. Agostinho, and J. C. Rubim, "Effect of sodium dodecylsulfate on copper corrosion in sulfuric acid media in the absence and presence of benzotriazole," Journal of Electroanalytical Chemistry, vol. 472, no. 2, pp. 112-119, 1999.

[40] L. Larabi, O. Benali, and Y. Harek, Portugaliae Electrochimica Acta, vol. 24, p. 337, 2006.

[41] M. A. Migahed, E. M. S. Azzam, and A. M. Al-Sabagh, Materials Chemistry and Physics, vol. 85, p. 273, 2004.

[42] A. Srhiri, F. Dabosi, and M. Etman, "Thiol compounds as corrosion inhibitors of carbon steel (XC 38) in sodium chloride 
medium," Werkstoffe und Korrosion, vol. 43, no. 8, pp. 406-414, 1992.

[43] H. Luo, Y. C. Guan, and K. N. Han, "Inhibition of mild steel corrosion by sodium dodecyl benzene sulfonate and sodium oleate in acidic solutions," Corrosion Science, vol. 54, article 619, 1998. 

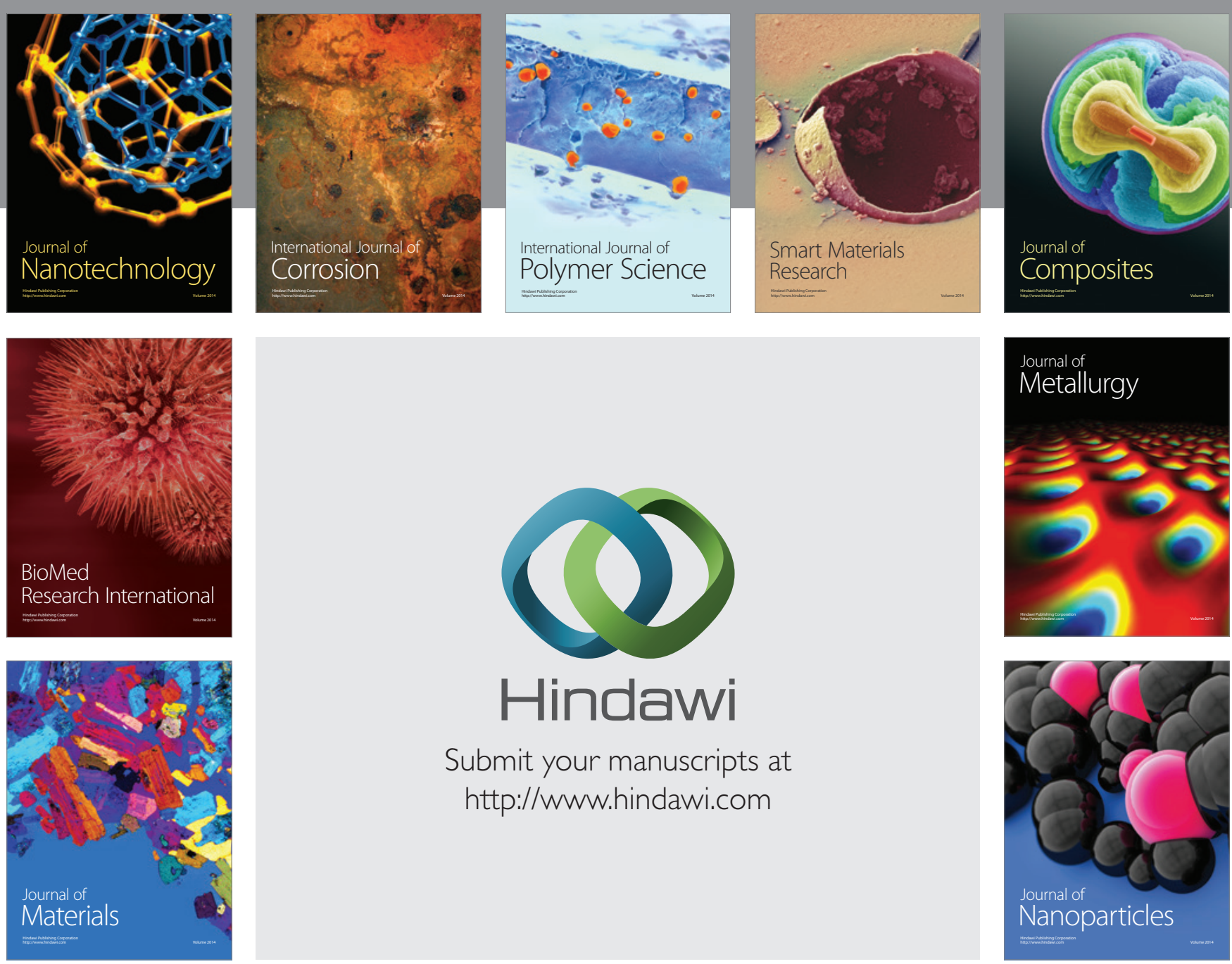

Submit your manuscripts at http://www.hindawi.com
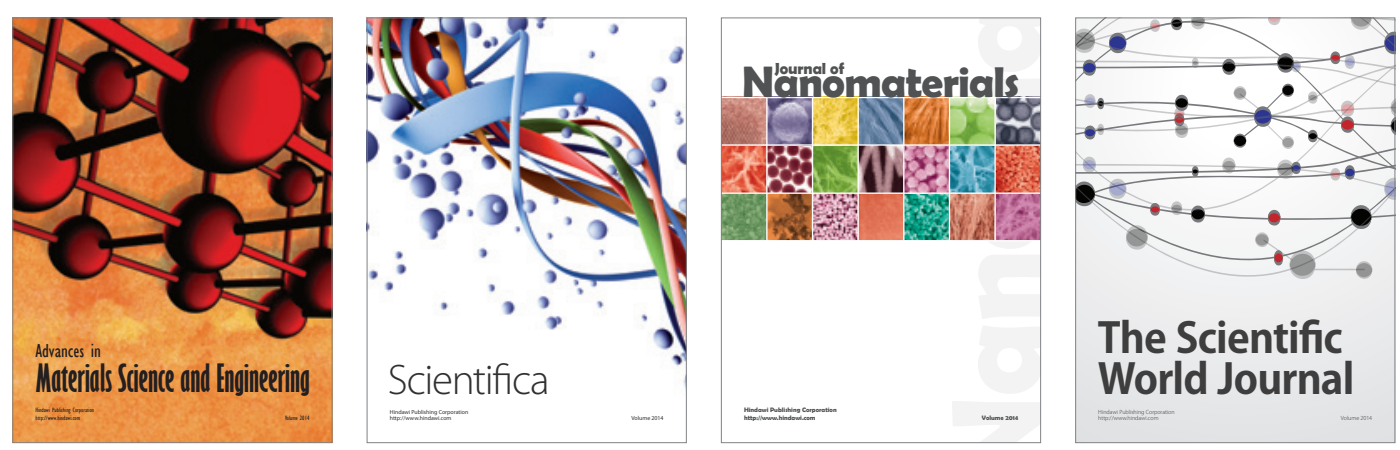

\section{The Scientific World Journal}
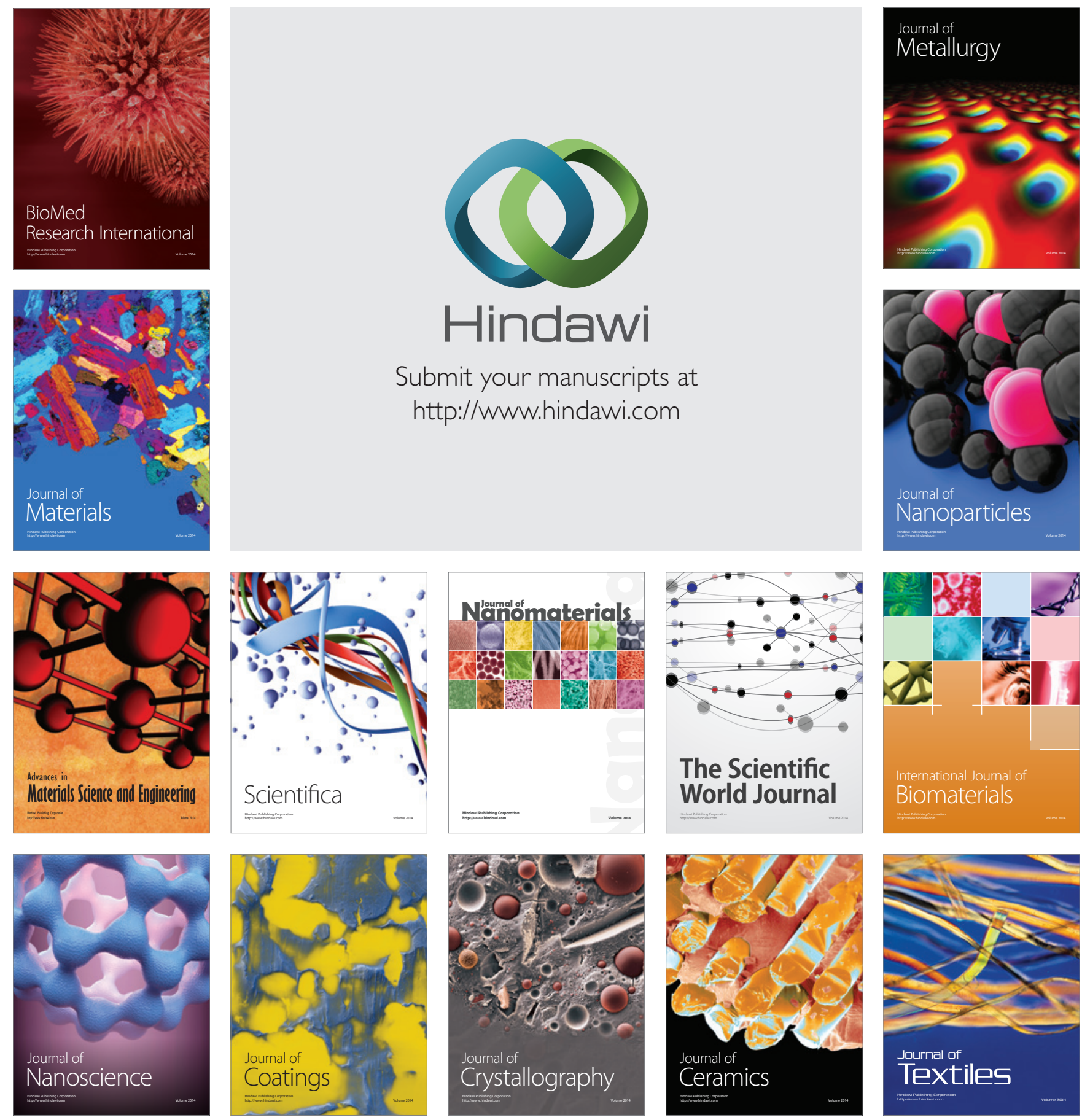